\title{
Inhibition of SUMO2/3 antagonizes isoflurane-induced cancer-promoting effect in hepatocellular carcinoma Hep3B cells
}

\author{
PENG WANG ${ }^{1,2}$, NA XUE $^{2,3}$, CHUNYAN ZHANG $^{4}$, SHIMIN SHAN $^{1,2}$, \\ ZHONGMIN JIANG ${ }^{2,5}$, WENHAN WU ${ }^{2,6}$ and XIAOZHI LIU ${ }^{2,3}$ \\ ${ }^{1}$ Department of Anesthesiology, ${ }^{2}$ Tianjin Key Laboratory of Epigenetics for Organ Development in Preterm Infants and \\ ${ }^{3}$ Central Laboratory, The Fifth Central Hospital of Tianjin; ${ }^{4}$ Department of Pharmacy, Binhai New Area Hospital of \\ Traditional Chinese Medicine; ${ }^{5}$ Department of Pathology, The Fifth Central Hospital of Tianjin, Tianjin 300450; \\ ${ }^{6}$ Department of General Surgery, Peking University First Hospital, Beijing 100031, P.R. China
}

Received July 3, 2020; Accepted January 7, 2021

DOI: $10.3892 / \mathrm{ol} .2021 .12535$

\begin{abstract}
Surgery for patients with complicated liver cancer often results in a long exposure to anesthesia with an increase in side effects. Continued long-term exposure to isoflurane may promote liver cancer progression. Small ubiquitin-like modifier (SUMO) 2 and 3, also known as SUMO2/3, conjugates to substrate proteins when cells undergo acute stress. However, whether or not SUMO2/3 is involved in isoflurane-mediated liver cancer progression is unknown. In the present study, hepatocellular carcinoma (HCC) cells were exposed to $2 \%$ isoflurane for $12 \mathrm{~h}$, followed by $36 \mathrm{~h}$ of drug withdrawal, and the formation of SUMO2/3 conjugates and cancer behavioral characteristics were studied. The results demonstrated that the formation of SUMO2/3 conjugates was significantly increased following HCC cells being exposed to isoflurane for $0.5 \mathrm{~h}$, and continued to increase for $48 \mathrm{~h}$, even after the drug had been withdrawn. Furthermore, isoflurane-exposed HCC cells exhibited increased proliferation and invasion activity during the subsequent observation period. SUMO specific protease 3 (SENP3), which inhibits the binding of SUMO2/3 to its target proteins, was overexpressed and it was discovered that isoflurane-induced SUMOylation was significantly inhibited, and accordingly, the proliferation and invasion abilities of HCC cells were decreased to a certain extent. These findings indicated that SUMO2/3 is involved in the progression of HCC cells, at
\end{abstract}

Correspondence to: Professor Wenhan Wu, Department of General Surgery, Peking University First Hospital, 8 Xishiku, Dajie Xicheng, Beijing 100031, P.R. China

E-mail:wuwenhan88@126.com

Dr Xiaozhi Liu, Central Laboratory, The Fifth Central Hospital of Tianjin, 41 Zhejiang Road, Tanggu, Binhai New Area, Tianjin 300450, P.R. China

E-mail: 1xz7997@126.com

Key words: small ubiquitin-like modifier, isoflurane, hepatocellular carcinoma, proliferation, invasion least in the Hep3B cell line, induced by the anesthetic isoflurane, and that inhibition of SUMO2/3 may antagonize the response. These results provided a novel target for decreasing the adverse reactions occurring in patients with HCC during anesthesia, particularly those who are exposed to isoflurane for long periods of time.

\section{Introduction}

Primary liver cancer is currently the fourth most common malignant tumor type and the third leading cause of mortality from cancer in China (1). There are three pathological types of primary liver cancer, including hepatocellular carcinoma (HCC), intrahepatic cholangiocarcinoma (ICC) and a mixed HCC-ICC type. Of these, HCC accounts for $85-90 \%$ of the cases (2). These cancers differ significantly in pathogenesis, biological behavior, histological morphology, treatment methods and prognosis (3). The diverse pathological types coupled with their characteristic rich blood supply dictate the specific surgical and anesthesia techniques used for treatment (4).

Almost all liver cancer surgeries are inevitably subject to prolonged anesthesia. Among all volatile anesthetics, isoflurane may be used to induce and maintain general anesthesia to eliminate the behavioral response of patients undergoing tumor resection (5). However, several studies have demonstrated that continuous isoflurane exposure results in the alteration of tumor cell behavior, including increased cell proliferation, invasion and metastasis. Huang et al (6) reported that isoflurane enhanced the proliferation and chemo-resistance of prostate cancer cells through regulating the HIF-1 $\alpha$ pathway. In non-small cell lung cancer cells, exposure to isoflurane promoted cancer cell proliferation by activating the Akt-mTOR signaling pathway (7). In addition, it was reported that, under exposure to isoflurane, melanoma grew faster in male mice than in female mice (8). In summary, these phenomena suggest that isoflurane exposure may be a promoting factor in the progression of the majority of cancer types (9).

SUMOylation, a form of protein post-translational modification, frequently contributes toward the malignant 
progression of tumors through involvement in various intracellular processes, including transcriptional regulation, nuclear transport, maintaining genomic integrity and signal transduction (10-13). In general, SUMO1 mediates delayed reactions, while SUMO2 and SUMO3 are involved in acute cellular stress responses (14). To date, it has not been determined whether isoflurane, a specific acute stress inducer, exerts its cancer-promoting effect on HCC by activating the SUMO2/3 pathway. In the present study, differences in SUMO2/3 protein expression were observed in HCC cells following isoflurane treatment and the effect of isoflurane on HCC cells was determined. The results indicated that isoflurane may significantly induce the activation of SUMO2/3 protein in HCC cells, characterized by an increase in the conjugated form of SUMO2/3 during the acute phase of isoflurane stimulation. Overexpression of SENP3 inhibited the binding of SUMO2/3 to the target protein, which significantly inhibited the isoflurane-induced activation of HCC cells. The results of the present study provide potential targets for anesthesiologists to decrease the side effects of anesthetic drugs during prolonged liver cancer surgery.

\section{Materials and methods}

HCC cell culture and isoflurane exposure. The human-derived hepatocellular carcinoma Hep3B cell line was purchased from the American Type Culture Collection (ATCC). The cells were placed in an incubator at $37^{\circ} \mathrm{C}$ with $5 \% \mathrm{CO}_{2}$ and cultured in Dulbecco's modified Eagle's medium (DMEM), supplemented with $10 \%$ fetal bovine serum (FBS), $100 \mathrm{U} / \mathrm{ml}$ penicillin and $100 \mu \mathrm{g} / \mathrm{ml}$ streptomycin (all Gibco; Thermo Fisher Scientific, Inc.). Prior to isoflurane exposure, the Hep3B cells were cultured in $60-\mathrm{mm}$ plates at a density of $1 \times 10^{6}$ cells per plate for $12 \mathrm{~h}$. The plates were then placed in a 1.5 -liter airtight chamber with a continuous flow of $2 \%$ isoflurane (Abbott Laboratories Ltd.), 21\% oxygen, 5\% carbon dioxide and $72 \%$ nitrogen for $12 \mathrm{~h}$, followed by a 36 -h period of drug withdrawal. The control group did not receive isoflurane treatment.

Gene transfection. A 2nd generation system was used for lentiviral transfection. The overexpressing vector for pWPXLD-GFP-SENP3 or pWPXLD-GFP (Biogot Technology, Co. Ltd.), the packaging plasmid, psPAX2 (Addgene, Inc.), and the envelope plasmid, pMD2.G (Addgene, Inc.), were transfected into 293T cells at the ratio of 4:3:1 for production of lentiviral particles. Lipofectamine $2000^{\mathrm{TM}}$ (Thermo Fisher Scientific, Inc.) was used as the transfection reagent, and the ratio of transfection reagent to plasmid was $1: 2.5$. The supernatant was filtered through a $0.45-\mu \mathrm{m}$ filter and was concentrated to $10^{8} \mathrm{PFU} / \mathrm{ml}$ by passing through an ultrafiltration tube (EMD Millipore). The concentrated virus was then aliquoted, snap frozen in liquid nitrogen and stored at $-80^{\circ} \mathrm{C}$ as soon as possible to avoid loss of titer. In order to improve the efficiency of infection, two infections were performed in total. First, the concentrated virus was used to infect Hep3B cells with $20-30 \%$ confluence $\left(5 \times 10^{5}\right.$ cells $)$ in a $60-\mathrm{mm}$ dish with $8 \mathrm{mg} / \mathrm{ml}$ polybrene. The cells were incubated at $37^{\circ} \mathrm{C}$ with $5 \% \mathrm{CO}_{2}$ for $\sim 18 \mathrm{~h}$, or until the following morning. Subsequently, the medium was carefully aspirated. The virus that had been aliquoted and preserved was used to infect Hep3B cells with 50-60\% confluence with $8 \mathrm{mg} / \mathrm{ml}$ polybrene a second time. Infected cells were selected using $1 \mathrm{mg} / \mathrm{ml}$ puromycin. After successfully obtaining stable cell lines, $0.5 \mathrm{mg} / \mathrm{ml}$ puromycin was used to maintain the stable cell system. After 15 days, gene transfection efficiency was verified by western blot analysis.

Western blot analysis. Total protein was extracted from Hep3B cells after $0.5,2,6$ and $12 \mathrm{~h}$ of isoflurane exposure, and under conditions of $12 \mathrm{~h}$ of isoflurane exposure, followed by drug withdrawal for a period of 12 or $36 \mathrm{~h}$ through incubation in RIPA buffer (Beijing Solarbio Science \& Technology Co., Ltd.), supplemented with $1 \mathrm{mM}$ phenylmethanesulfonyl fluoride and $20 \mathrm{mM}$ N-ethylmaleimide. Bicinchoninic acid assay (cat. no. PC0020; Beijing Solarbio Science \& Technology Co., Ltd.) was used for protein quantification. Subsequently, $100 \mu \mathrm{g}$ protein was separated on 4-12\% SDS-PAGE gels, transferred onto polyvinylidene fluoride membranes (EMD Millipore, Inc.), blocked with 5\% skimmed milk and $0.1 \%$ Tris-buffered saline with $1 \mathrm{ml} / 1$ Tween-20 for $1 \mathrm{~h}$ at $37^{\circ} \mathrm{C}$, and incubated with specific antibodies overnight at $4^{\circ} \mathrm{C}$ following the parameters provided in Table I. The membranes were then incubated for $1 \mathrm{~h}$ at room temperature with horseradish peroxidase-conjugated mouse anti-rabbit $\operatorname{IgG}(1: 2,000$; cat. no. sc-2357; Santa Cruz Biotechnology, Inc.) or goat anti-chicken IgY H\&L (1:2,000; cat. no. ab6877; Abcam) secondary antibodies. A Super Signal protein detection kit (cat. no. 34095; Pierce; Thermo Fisher Scientific, Inc.) was used to detect protein signals according to the manufacturer's protocol. Following development, the value of each band was quantified by ImageJ version 1.48 image analysis software (National Institutes of Health).

Cell proliferation assay. The proliferation activity of tumor cells was measured using the Cell Counting kit-8 (CCK-8; Shanghai Yeasen Biotechnology Co., Ltd.). Hep3B cells were cultured in 96-well plates for $24 \mathrm{~h}$ in normal medium, followed by a $12 \mathrm{~h}$ isoflurane exposure. The culture media was then replaced with fresh media, and cells were cultured for an additional $36 \mathrm{~h}$. To determine the proliferation rate of the tumor cells, CCK- $8(5 \mathrm{mg} / \mathrm{ml})$ was added to each well and the cells were incubated for $1 \mathrm{~h}$, followed by measuring the absorbance of each well at $450 \mathrm{~nm}$ using a microplate reader (Bio-Rad Laboratories, Inc.). Finally, the absorbance values were used to derive the relative cell number from a standard curve.

Wound healing assay. When cell confluence in a 6-well plate reached $90 \%$, the Hep3B cells were exposed to $2 \%$ isoflurane for $12 \mathrm{~h}$ in DMEM supplemented with 10\% FBS. The plates were removed and the medium was replaced with serum-free DMEM. The surface of the cells was lightly scratched using a $200 \mu 1$ pipette tip to create a wound healing model. The scratch width was measured and recorded as S0 under a light microscope (magnification, x200; Olympus cellSens Entry 1.16; Olympus Corporation). After $36 \mathrm{~h}$ of routine culture in serum-free DMEM, the distance between the two sides of the 
Table I. Information regarding all antibodies used in the present study.

\begin{tabular}{|c|c|c|c|c|c|c|}
\hline Antibody & SUMO2/3 & SENP3 & GFP & $\beta$-actin & $\operatorname{IgG}$ & $\operatorname{IgY}$ \\
\hline Supplier & Abcam & Abcam & Abcam & Abcam & Santa Cruz Biotechnology, Inc. & Abcam \\
\hline Catalog no. & ab3742 & ab124790 & ab13970 & $\mathrm{ab} 8227$ & sc-2357 & ab6877 \\
\hline Dilution factor & $1: 1,000$ & $1: 2,000$ & $1: 5,000$ & $1: 1,000$ & $1: 2,000$ & $1: 2,000$ \\
\hline
\end{tabular}

SENP3, SUMO specific protease 3; SUMO2/3, small ubiquitin-like modifier 2/3.

scratch was measured again and recorded as $\mathrm{S} 1$. The actual healing distance was calculated by S0-S1.

Invasion assay. The invasion capacity of the tumor cells was detected using a Transwell culture chamber. In brief, $1 \times 10^{4}$ Hep3B cells were seeded into the upper chambers precoated with Matrigel overnight at $37^{\circ} \mathrm{C}$ (BD Biosciences), and the lower chambers remained empty. Next, the Transwell chamber was transferred into an airtight chamber and exposed to $2 \%$ isoflurane for $12 \mathrm{~h}$. The Transwell culture chamber was then removed and the medium in the upper chambers was replaced with serum-free DMEM, and DMEM medium containing $10 \%$ FBS was added to the lower chambers. After $36 \mathrm{~h}$ of culture at $37^{\circ} \mathrm{C}$, the membrane of the upper chamber was stained with crystal violet for $10 \mathrm{~min}$ at room temperature. The number of invading cells was counted under an inverted light microscope (magnification, x200; Olympus cellSens Entry 1.16; Olympus Corporation).

Statistical analysis. The data are presented as the mean \pm standard deviation and were analyzed using GraphPadPrism 6 software. Comparisons between two groups were performed using a Student's t-test. Differences between multiple groups were analyzed by a one-way analysis of variance followed by Tukey's test. $\mathrm{P}<0.05$ was considered to indicate a statistically significant difference. All the experiments were repeated three times.

\section{Results}

Isoflurane exposure significantly increases the number of SUMO2/3 conjugates. SUMO2 and SUMO3 are two members of the SUMO family that participate in the acute stress response. To observe the effect of isoflurane exposure on SUMO2/3 protein expression, the human-derived HCC Hep3B line was exposed to $2 \%$ isoflurane for 0.5 , 2, 6 and $12 \mathrm{~h}$. The results indicated that a short period of isoflurane exposure resulted in significant changes in the expression of SUMO2/3 protein in hepatoma cells. This was manifested by an increased number of SUMO2/3 conjugates at $0.5 \mathrm{~h}$ of isoflurane exposure, and this upward trend continued with prolonged exposure to isoflurane (Fig. 1A and B). To determine whether the number of SUMO2/3 conjugates changes following the withdrawal of isoflurane, the HCC cells were exposed to isoflurane for $12 \mathrm{~h}$, and the cells were cultured in fresh medium without isoflurane for an additional $12 \mathrm{~h}$ (total $24 \mathrm{~h}$ ) and $36 \mathrm{~h}$ (total
$48 \mathrm{~h}$ ). The results indicated that the number of SUMO2/3 conjugates continued to increase until $48 \mathrm{~h}$, and this upward trend did not change following the withdrawal of isoflurane (Fig. 1A and B).

Isoflurane exposure promotes malignant progression of liver cancer cells. Next, the effects of isoflurane exposure on the behavior of liver cancer cells were investigated. The results of the CCK-8 experiment demonstrated that HCC cells exhibited a faster proliferation rate following exposure to isoflurane for $12 \mathrm{~h}$ (Fig. 2A). The effects of isoflurane on liver cancer cell migration and invasion were then examined. The results indicated that the tumor cells exposed to isoflurane exhibited a stronger migration (Fig. 2B and C) and invasion ability (Fig. 2D and E). These results indicated that isoflurane exposure promotes the proliferation, migration and invasion of HCC cells and induces the malignant progression of liver cancer.

Overexpression of SENP3 effectively inhibits the generation of SUMO2/3 conjugates. It has been reported that SENP3 may specifically inhibit the binding of SUMO2/3 to its target proteins. Therefore, SENP3 was overexpressed in HCC cells through gene transfection and the resulting number of SUMO2/3 conjugates were detected by western blot analysis. The results demonstrated that the control HCC cells expressed lower levels of SENP3 protein (Fig. 3A and B). By contrast, gene transfection significantly increased the expression level of SENP3 protein in HCC cells. As a result, the ability of SUMO2/3 to bind to its target protein was inhibited and the number of SUMO2/3 conjugates was significantly decreased (Fig. 3A and B).

Inhibition of SUMO2/3 disrupts the malignant progression of liver cancer cells exposed to isoflurane. The effect of inhibiting the number of SUMO2/3 conjugates on the progression of liver cancer cells exposed to isoflurane was investigated by overexpressing SENP3. The results of cell proliferation experiments revealed that overexpression of SENP3 antagonized isoflurane-induced proliferation of HCC cells (Fig. 4A). Furthermore, inhibition of SUMO2/3 conjugate formation by overexpression of SENP3 significantly inhibited the migration (Fig. 4B and C) and invasion (Fig. 4D and E) of HCC cells resulting from isoflurane exposure. Taken together, these results indicated that overexpression of SENP3 may effectively inhibit the generation of SUMO2/3 conjugates and antagonize the malignant progression of liver cancer cells induced by isoflurane exposure. 

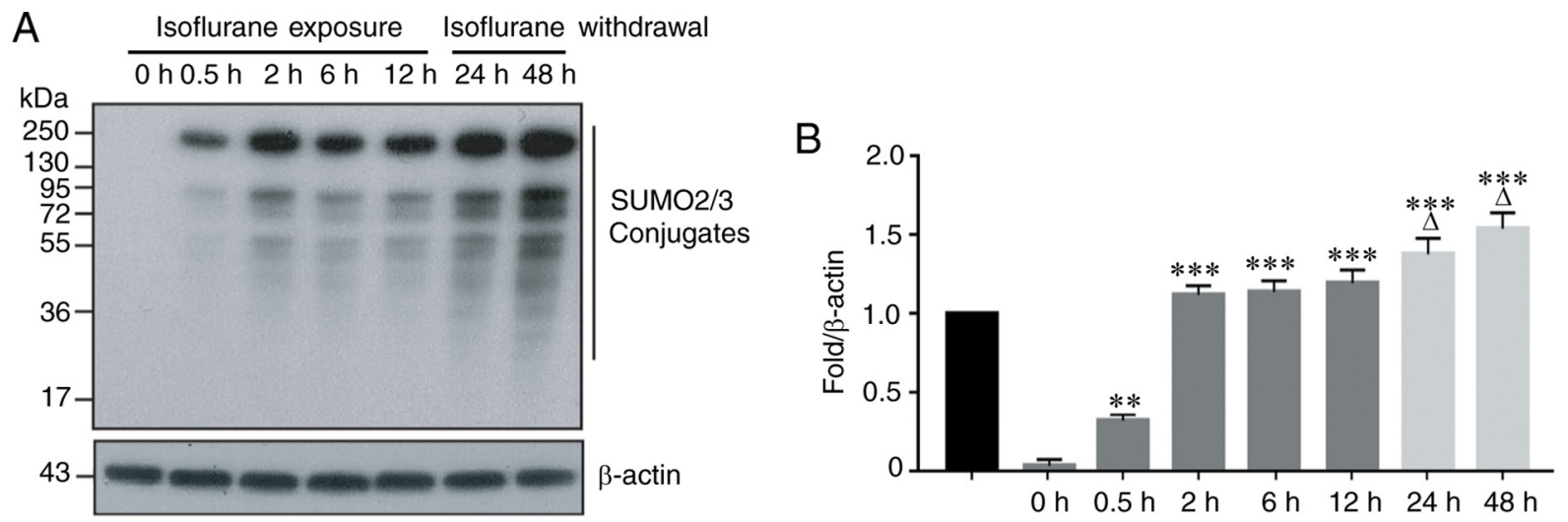

Figure 1. Isoflurane increases the production of SUMO2/3 conjugates in hepatocellular carcinoma cells. (A) The protein expression of SUMO2/3 conjugates was determined by Western blot analysis. (B) Bar graph from A. Data are presented as the means \pm standard deviation $(\mathrm{n}=3){ }^{* * * *} \mathrm{P}<0.01$ or ${ }^{* * * *} \mathrm{P}<0.001$, compared with the $0 \mathrm{~h}$ group. ${ }^{\mathrm{P}} \mathrm{P}<0.05$, compared with the $12 \mathrm{~h}$ group. SUMO2/3, small ubiquitin-like modifier $2 / 3$.

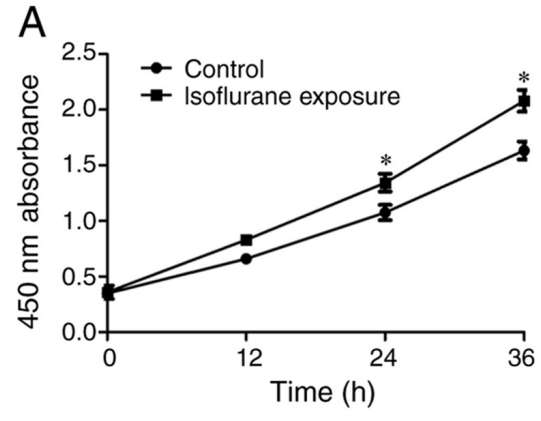

C

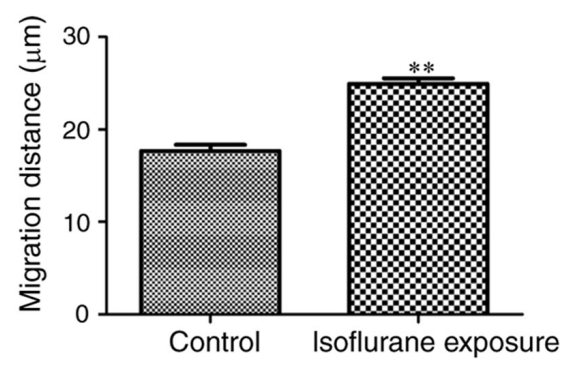

$\mathrm{E}$

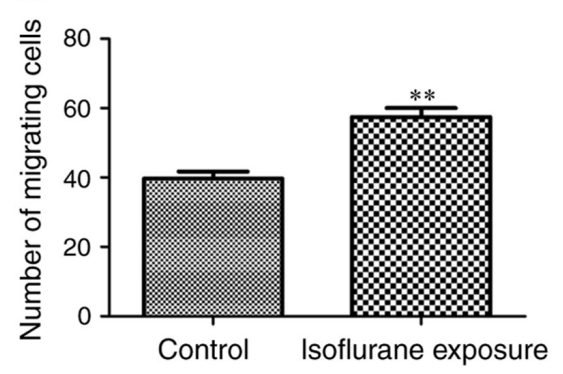

B

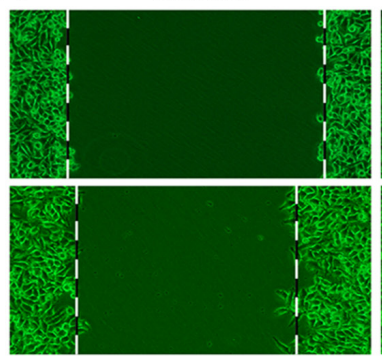

$\mathrm{D}$

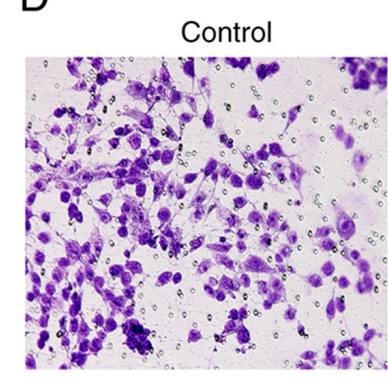

Isoflurane exposure

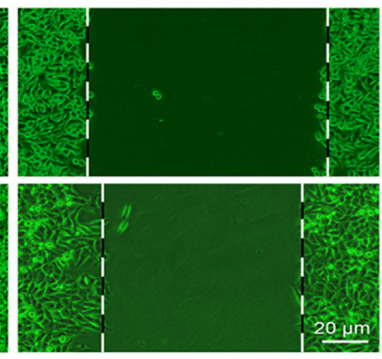

Isoflurane exposure

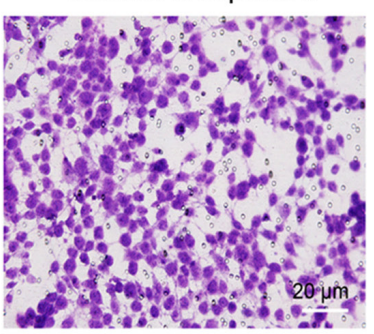

Figure 2. Isoflurane exposure promotes the malignant progression of HCC cells. (A) The proliferation activity of HCC cells was evaluated using a Cell Counting kit- 8 assay. (B and C) The migratory ability of HCC cells was determined by a wound healing experiment (scale bar, $20 \mu \mathrm{m}$ ). (D and E) The invasive ability of HCC cells was determined by a Transwell experiment (scale bar, $20 \mu \mathrm{m}$ ). Data are presented as the mean \pm standard deviation ( $=8$ ); ${ }^{*} \mathrm{P}<0.05$, ${ }^{* *} \mathrm{P}<0.01$, compared with the control group. HCC, hepatocellular carcinoma.

\section{Discussion}

In China, liver cancer accounts for the second highest mortality rate from malignant tumors in cities and represents the highest mortality rate in certain rural areas (15). Guangxi
Province has experienced a particularly high incidence of liver cancer in mainland China (16). At present, surgery remains the primary treatment method for liver cancer (17). The pathological type, tumor volume, intrahepatic location, invasive disease and distant metastasis affect the duration 

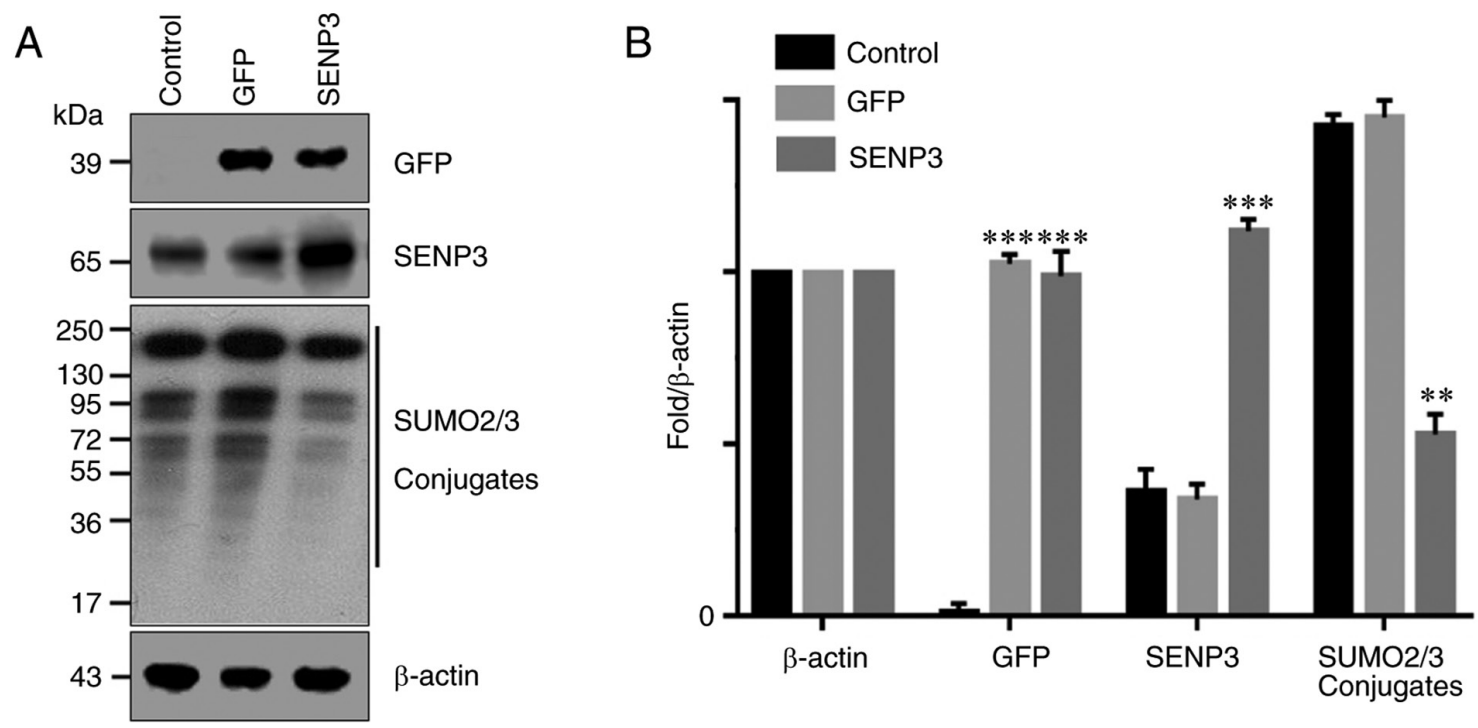

Figure 3. SENP3 overexpression inhibits SUMO2/3 conjugate formation. (A) Protein expression was investigated by Western blot analysis. (B) Bar graph of data from A. Data are presented as the mean \pm standard deviation $(n=3) ;{ }^{* *} \mathrm{P}<0.01$ or ${ }^{* * *} \mathrm{P}<0.001$, compared with the 0 h group. SENP3, SUMO specific protease 3; SUMO2/3, small ubiquitin-like modifier 2/3.

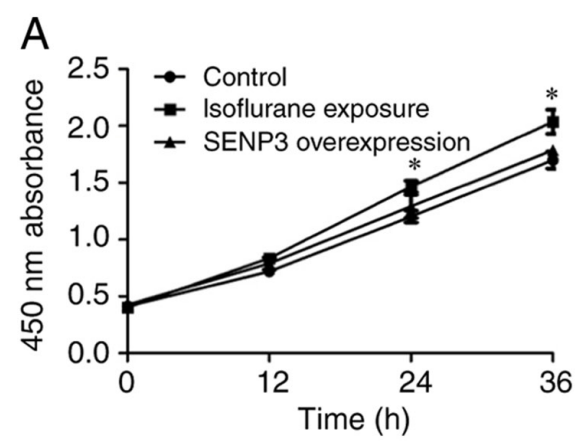

C

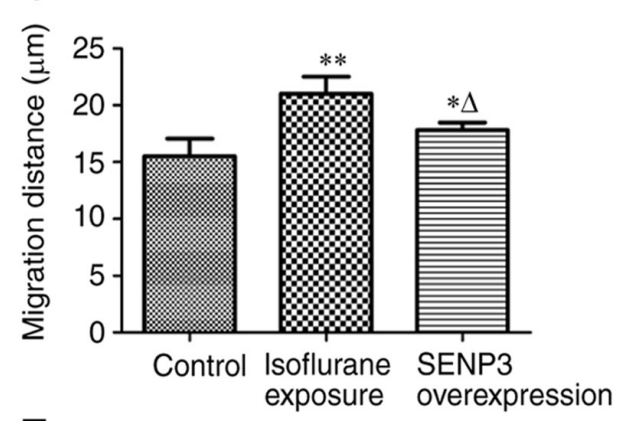

E

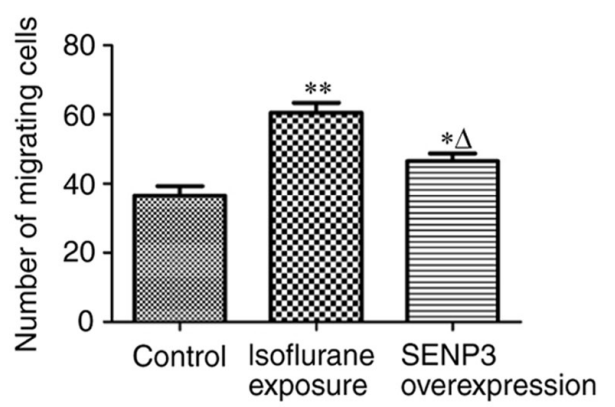

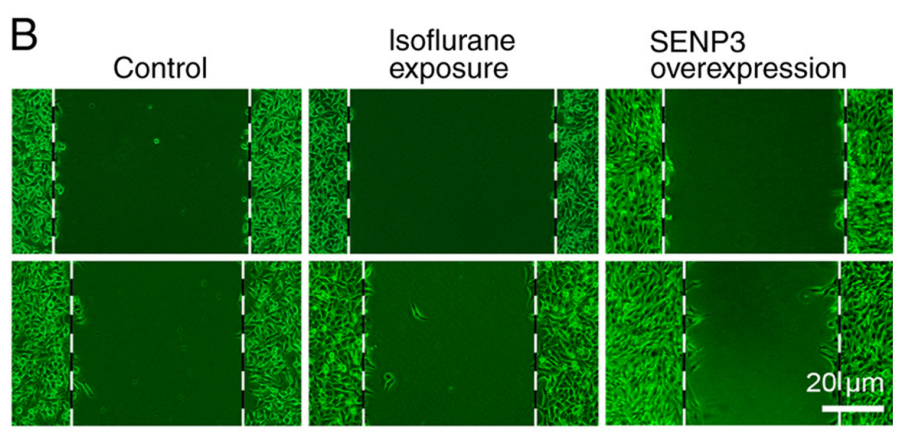

D Control $\quad \begin{array}{ll}\text { Isoflurane } & \text { SENP3 } \\ \text { exposure } & \text { overexpression }\end{array}$

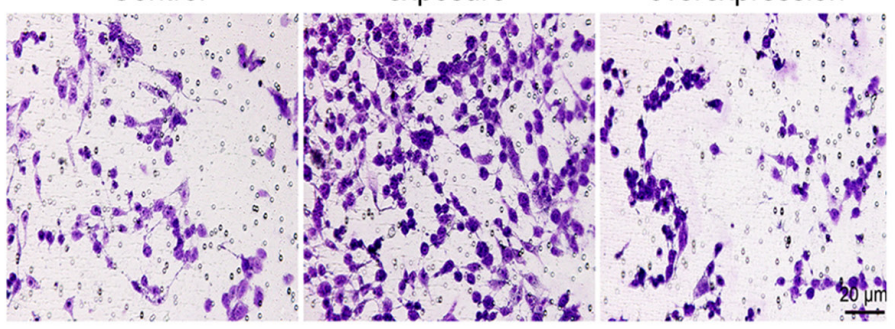

Figure 4. SENP3 overexpression antagonizes the malignant progression of HCC cells caused by isoflurane exposure. (A) Proliferation of HCC cells was determined by a Cell Counting kit-8 assay. (B and C) The migratory ability of HCC cells was determined using a wound healing assay (scale bar, $20 \mu \mathrm{m}$ ). (D and E) The invasive ability of HCC cells was determined by a Transwell experiment (scale bar, $20 \mu \mathrm{m}$ ). Data are presented as the mean $\pm \mathrm{SD}(\mathrm{n}=8)$; ${ }^{*} \mathrm{P}<0.05$, ${ }^{* *} \mathrm{P}<0.01$, compared with the control group. ${ }^{4} \mathrm{P}<0.05$, compared with the isoflurane exposure group. SENP3, SUMO specific protease 3; HCC, hepatocellular carcinoma. 
of liver cancer surgery and expose patients to anesthesia for extended periods of time (17). It is generally believed that short-term exposure to narcotic drugs does not cause significant adverse effects in patients (18). However, inappropriate drug selection, long-term anesthetic drug exposure and the quality of patient liver function, may affect long-term prognosis (19). Therefore, elderly and frail patients and those with abnormal liver function are given extra attention by anesthesiologists.

Among narcotic drugs, halogen anesthetics, including sevoflurane, isoflurane and enflurane, are the main gas anesthetics that are widely used clinically (20). They are inhaled in gaseous form, incorporated into the blood circulation and transported to the central nervous system where they exert an anesthetic effect. Halogen anesthetics have several advantages, including a strong effect, rapid induction of anesthesia, quick patient recovery and ease of use (21). Therefore, they have remained a cornerstone in general anesthesia.

However, a problem that should not be overlooked is that inhaled anesthetics exhibit liver toxicity. Halothane is the most commonly used drug that causes liver toxicity (22). Compared with halothane, the incidence of liver toxicity with sevoflurane, enflurane, isoflurane and other halogenated inhalation anesthetics is significantly decreased, but not completely eradicated (23). These halogenated inhalation anesthetics are oxidized and metabolized by P4502E1 isoenzymes to produce substances similar to the intermediate products of halothane metabolism (24). Therefore, these drugs exhibit similar activity coupled with mild hepatotoxicity. A recent study revealed that insulin-like growth factor 1 (IGF-1) levels are downregulated following exposure to isoflurane anesthesia (25). IGF-1 may be involved in the liver injury mechanism induced by exposure to isoflurane (25). However, another group demonstrated that isoflurane inhibits hepatic carcinoma growth and aggressiveness, and promotes apoptosis through the PI3K/Akt-mediated NF- $\mathrm{KB}$ signaling pathway (9). Although these results appear to be contradictory, the results were obtained using primary cultured cells from patients receiving general anesthesia, isoflurane, intravenous medication or even tissue damage caused by surgery. We hypothesize that different methods of anesthesia result in different experimental conclusions. Lai et al (5) reported that during open hepatectomy for HCC, the use of propofol anesthesia was associated with longer survival times compared with desflurane. Patients receiving propofol anesthesia exhibited a significant decrease in distant metastasis and local recurrence (5).

Another issue that should be considered is that specific types of inhaled anesthetics, or long-term exposure to certain anesthetics, may cause unpredictable consequences in tumors (26). The present study focused on the biological response of HCC cells following isoflurane exposure. The identification of novel molecular mechanisms may lead to interventions against these molecular targets to decrease the adverse effects of isoflurane on HCC cells. SUMOylation, mediated by members of the SUMO family, is widely involved in various cellular responses to external stimuli and internal microenvironmental changes (27). SUMO1 is involved in delayed cellular responses, whereas SUMO2/3 is primarily involved in acute stress responses $(14,28)$. In general, simple liver cancer surgery lasts $2-5 \mathrm{~h}$, while complex liver cancer resection plus lymph node dissection may require $10 \mathrm{~h}$ or more. Therefore, in the present study, changes in SUMO2/3 conjugates were investigated at different time points during early isoflurane exposure. The results of the present study indicated that isoflurane exposure for $0.5 \mathrm{~h}$ may induce a significant increase in SUMO2/3 conjugates, and this upward trend continued with increased isoflurane exposure time. Considering that patients undergoing refractory liver cancer surgery may receive anesthesia for more than ten $h$, the maximum exposure time of isoflurane was limited to $12 \mathrm{~h}$, and the subsequent changes in SUMO2/3 conjugates following isoflurane withdrawal were observed. The results demonstrated that the increased number of SUMO2/3 conjugates did not abate with the withdrawal of isoflurane. By contrast, the number of SUMO2/3 conjugates continued to increase up to $48 \mathrm{~h}$ after detection. The effect of isoflurane exposure on the HCC cell phenotype was then investigated. The results demonstrated that isoflurane exposure increased the proliferation, migration and invasion activity of HCC cells.

It is generally recognized that SENP3 may effectively dissociate SUMO2/3 from its substrates (29). Therefore, in follow-up experiments, SENP3 was overexpressed in HCC cells by gene transfection, which effectively inhibited the generation of SUMO2/3 conjugates. The SUMO2/3 substrates that have been identified thus far include Akt, HIF-1 $\alpha$, Oct 4 , CDK6 and dozens of other proteins involved in tumor cell proliferation, migration and invasion (30-35). A recent study in rats demonstrated that increased levels of Heat shock protein 27 resulting from SUMO2/3-mediated SUMOylation serve an important role in the progression of primary hepatocellular carcinoma (36). This finding may provide insight for the development of novel therapeutic drugs to treat primary hepatocellular carcinoma (36).

In the present study, the specific proteins that are activated by isoflurane exposure to generate conjugates with SUMO2/3 were not investigated, but such investigations should be made in the future by targeting SUMO2/3 with proteomics technology. Nevertheless, it remains likely that isoflurane participates in the malignant progression of $\mathrm{HCC}$ cells by activating SUMO2/3 and increasing the formation of conjugates. Inhibiting the generation of SUMO2/3 conjugates by overexpressing SENP3 also antagonizes the progression of cancer cells resulting from isoflurane exposure.

In conclusion, it was confirmed that short-term $(<12 \mathrm{~h})$ isoflurane exposure results in the activation of $\mathrm{SUMO} 2 / 3$ and increases the formation of conjugates, thereby promoting the malignant progression of HCC cells. Therefore, on the basis of the results of the present study, we hypothesize that targeted inhibition of SUMO2/3 conjugate formation may antagonize the progression of HCC caused by isoflurane exposure. However, the Hep3B cell line was derived from an 8-year-old black male with HCC (37) and is different from HCC cells derived from adults $(38,39)$. Therefore, further studies are required using additional liver cancer cell lines, including those derived from adults, various tumor types and animal experiments. Furthermore, as the role of SUMO2/3 expression in the progression of HCC cells remains unclear, further investigations are required in future studies. 


\section{Acknowledgements}

Not applicable.

\section{Funding}

The present study was supported by grants from National Natural Science Foundation of China (grant nos. 81901526 and 81900407), Tianjin Natural Science Foundation of China (grant nos. 18JCQNJC12800, 19JCZDJC35200, 19JCQNJC12100 and 19JCQNJC11900), Tianjin Special Project of New Generation Artificial Intelligence Technology (grant no. 18ZXZNSY00260) and Binhai Health and Family Planning Commission Science and Technology Projects (grant nos. 2019BWKQ030 and 2019BWKQ029).

\section{Availability of data and materials}

The datasets used and/or analyzed during the present study are available from the corresponding author on reasonable request.

\section{Authors' contributions}

WW designed the experiments. PW, XL, CZ, ZJ and NX performed the experiments and collected data. WW and SS analyzed and interpreted the data. PW, XL and CZ drafted the manuscript. WW agreed to be accountable for all aspects of the work in ensuring that questions related to the accuracy or integrity of any part of the work are appropriately investigated and resolved. All authors read and approved the final manuscript.

\section{Ethics approval and consent to participate}

Not applicable.

\section{Patient consent for publication}

Not applicable.

\section{Competing interests}

The authors declare that they have no competing interests.

\section{References}

1. Chao J, Zhao S and Sun H: Dedifferentiation of hepatocellular carcinoma: Molecular mechanisms and therapeutic implications. Am J Transl Res 12: 2099-2109, 2020.

2. Garin E, Palard X and Rolland Y: Personalised dosimetry in radioembolisation for HCC: Impact on clinical outcome and on trial design. Cancers (Basel) 12: 1557, 2020.

3. Tellapuri S, Sutphin PD, Beg MS, Singal AG and Kalva SP: Staging systems of hepatocellular carcinoma: A review. Indian J Gastroenterol 37: 481-491, 2018.

4. Glantzounis GK, Paliouras A, Stylianidi MC, Milionis H, Tzimas P, Roukos D, Pentheroudakis G and Felekouras E: The role of liver resection in the management of intermediate and advanced stage hepatocellular carcinoma. A systematic review. Eur J Surg Oncol 44: 195-208, 2018.

5. Lai HC, Lee MS, Lin C, Lin KT, Huang YH, Wong CS, Chan SM and Wu ZF: Propofol-based total intravenous anaesthesia is associated with better survival than desflurane anaesthesia in hepatectomy for hepatocellular carcinoma: A retrospective cohort study. Br J Anaesth 123: 151-160, 2019.
6. Huang H, Benzonana LL, Zhao H, Watts HR, Perry NJ, Bevan C, Brown R and Ma D: Prostate cancer cell malignancy via modulation of HIF-1 $\alpha$ pathway with isoflurane and propofol alone and in combination. Br J Cancer 111: 1338-1349, 2014.

7. Zhang $\mathrm{W}$ and Shao X: Isoflurane promotes non-small cell lung cancer malignancy by activating the Akt-mammalian target of rapamycin (mTOR) signaling pathway. Med Sci Monit 22: 4644-4650, 2016.

8. Meier A, Gross ETE, Schilling JM, Seelige R, Jung Y, Santosa E, Searles S, Lin T, Tu XM, Patel HH and Bui JD: Isoflurane impacts murine melanoma growth in a sex-specific, immune-dependent manner: A brief report. Anesth Analg 126: 1910-1913, 2018.

9. $\mathrm{Hu} \mathrm{J}, \mathrm{Hu}$ J, Jiao $\mathrm{H}$ and $\mathrm{Li} \mathrm{Q}$ : Anesthetic effects of isoflurane and the molecular mechanism underlying isoflurane-inhibited aggressiveness of hepatic carcinoma. Mol Med Rep 18: 184-192, 2018.

10. Seeler JS and Dejean A: SUMO and the robustness of cancer. Nat Rev Cancer 17: 184-197, 2017.

11. Flotho A and Melchior F: Sumoylation: A regulatory protein modification in health and disease. Annu Rev Biochem 82: 357-385, 2013.

12. Geiss-Friedlander R and Melchior F: Concepts in sumoylation: A decade on. Nat Rev Mol Cell Biol 8: 947-956, 2007.

13. Henley JM, Craig TJ and Wilkinson KA: Neuronal SUMOylation: Mechanisms, physiology, and roles in neuronal dysfunction. Physiol Rev 94: 1249-1285, 2014.

14. Chang SC and Ding JL: Ubiquitination and SUMOylation in the chronic inflammatory tumor microenvironment. Biochim Biophys Acta Rev Cancer 1870: 165-175, 2018.

15. Qiu G, Jin Z, Chen X and Huang J: Interpretation of guidelines for the diagnosis and treatment of primary liver cancer (2019 edition) in China. Glob Health Med 2: 306-311, 2020.

16. Pang Y, Kartsonaki C, Turnbull I, Guo Y, Chen Y, Clarke R, Bian Z, Bragg F, Millwood IY, Yang L, et al: Adiposity in relation to risks of fatty liver, cirrhosis and liver cancer: A prospective study of 0.5 million Chinese adults. Sci Rep 9: 785, 2019.

17. McCarty TR, Echouffo-Tcheugui JB, Lange A, Haque L and Njei B: Impact of bariatric surgery on outcomes of patients with nonalcoholic fatty liver disease: A nationwide inpatient sample analysis, 2004-2012. Surg Obes Relat Dis 14: 74-80, 2018.

18. Pinto RZ, Maher CG, Ferreira ML, Ferreira PH, Hancock M, Oliveira VC, McLachlan AJ and Koes B: Drugs for relief of pain in patients with sciatica: Systematic review and meta-analysis. BMJ 344: e497, 2012.

19. Komaki Y, Komaki F, Micic D, Ido A and Sakuraba A: Risk of colorectal cancer in chronic liver diseases: A systematic review and meta-analysis. Gastrointest Endosc 86: 93-104.e5, 2017.

20. Antipass A, Austin A, Awad S, Hughes D and Idris I: Evaluation of liver function tests and risk score assessment to screen patients for significant liver disease prior to bariatric and metabolic surgery. Obes Surg 30: 2840-2843, 2020.

21. Ikuta S, Tanimura K, Yasui C, Aihara T, Yoshie H, Iida H, Beppu N, Kurimoto A, Yanagi H, Mitsunobu M and Yamanaka N: Chronic liver disease increases the risk of linezolid-related thrombocytopenia in methicillin-resistant Staphylococcus aureus-infected patients after digestive surgery. J Infect Chemother 17: 388-391, 2011.

22. Esser T, Keilhoff $\mathrm{G}$ and Ebmeyer U: Anesthesia specific differences in a cardio-pulmonary resuscitation rat model; halothane versus sevoflurane. Brain Res 1652: 144-150, 2016.

23. Dugan CM, Fullerton AM, Roth RA and Ganey PE: Natural killer cells mediate severe liver injury in a murine model of halothane hepatitis. Toxicol Sci 120: 507-518, 2011.

24. Yin $\mathrm{H}$, Cheng L, Langenbach R and Ju C: Prostaglandin I(2) and $\mathrm{E}(2)$ mediate the protective effects of cyclooxygenase-2 in a mouse model of immune-mediated liver injury. Hepatology 45: 159-169, 2007.

25. Zhu Y, Xiao X, Li G, Bu J, Zhou W and Zhou S: Isoflurane anesthesia induces liver injury by regulating the expression of insulin-like growth factor 1. Exp Ther Med 13: 1608-1613, 2017.

26. Feng D, Wang Y, Xu Y, Luo Q, Lan B and Xu L: Interleukin 10 deficiency exacerbates halothane induced liver injury by increasing interleukin 8 expression and neutrophil infiltration. Biochem Pharmacol 77: 277-284, 2009.

27. Delgado TC, Lopitz-Otsoa F and Martínez-Chantar ML: Post-translational modifiers of liver kinase B1/serine/threonine kinase 11 in hepatocellular carcinoma. J Hepatocell Carcinoma 6: 85-91, 2019.

28. Jin ZL, Pei H, Xu YH, Yu J and Deng T: The SUMO-specific protease SENP5 controls DNA damage response and promotes tumorigenesis in hepatocellular carcinoma. Eur Rev Med Pharmacol Sci 20: 3566-3573, 2016. 
29. Kim DH, Kwon S, Byun S, Xiao Z, Park S, Wu SY, Chiang CM Kemper B and Kemper JK: Critical role of RanBP2-mediated SUMOylation of small heterodimer partner in maintaining bile acid homeostasis. Nat Commun 7: 12179, 2016.

30. Xia W, Tian H, Cai X, Kong H, Fu W, Xing W, Wang Y, Zou M, $\mathrm{Hu} \mathrm{Y}$ and $\mathrm{Xu} \mathrm{D}$ : Inhibition of SUMO-specific protease 1 induces apoptosis of astroglioma cells by regulating NF- $\mathrm{BB} / \mathrm{Akt}$ pathways. Gene 595: 175-179, 2016.

31. Lin CH, Liu SY and Lee EH: SUMO modification of Akt regulates global SUMOylation and substrate SUMOylation specificity through Akt phosphorylation of Ubc9 and SUMO1. Oncogene 35: 595-607, 2016.

32. Risso G, Pelisch F, Pozzi B, Mammi P, Blaustein M, Colman-Lerner A and Srebrow A: Modification of Akt by SUMO conjugation regulates alternative splicing and cell cycle. Cell Cycle 12: 3165-3174, 2013.

33. Carbia-Nagashima A, Gerez J, Perez-Castro C, Paez-Pereda M, Silberstein S, Stalla GK, Holsboer F and Arzt E: RSUME, a small RWD-containing protein, enhances SUMO conjugation and stabilizes HIF-1alpha during hypoxia. Cell 131: 309-323, 2007.

34. Wei F, Schöler HR and Atchison ML: Sumoylation of Oct4 enhances its stability, DNA binding, and transactivation. J Biol Chem 282: 21551-21560, 2007.
35. Xu Y,Li J,Zuo Y,Deng J, Wang LS and Chen GQ: SUMO-specific protease 1 regulates the in vitro and in vivo growth of colon cancer cells with the upregulated expression of CDK inhibitors. Cancer Lett 309: 78-84, 2011

36. Ge H, Du J, Xu J, Meng X, Tian J, Yang J and Liang H: SUMOylation of HSP27 by small ubiquitin-like modifier $2 / 3$ promotes proliferation and invasion of hepatocellular carcinoma cells. Cancer Biol Ther 18: 552-559, 2017.

37. Knowles BB, Howe CC and Aden DP: Human hepatocellular carcinoma cell lines secrete the major plasma proteins and hepatitis B surface antigen. Science 209: 497-499, 1980.

38. Knasmuller S, Parzefall W, Sanyal R, Ecker S, Schwab C, Uhl M, Mersch-Sundermann V, Williamson G, Hietsch G, Langer T, et al: Use of metabolically competent human hepatoma cells for the detection of mutagens and antimutagens. Mutat Res 402: 185-202, 1998.

39. Qiu GH, Xie X, Xu F, Shi X, Wang Y and Deng L: Distinctive pharmacological differences between liver cancer cell lines HepG2 and Hep3B. Cytotechnology 67: 1-12, 2015.

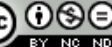

This work is licensed under a Creative Commons Attribution-NonCommercial-NoDerivatives 4.0 International (CC BY-NC-ND 4.0) License. 